\title{
Desvelando a Netnografia: um guia teórico e prático
}

DOI: $10.1590 / 1809-58442015217$

Suelen de Aguiar Silva

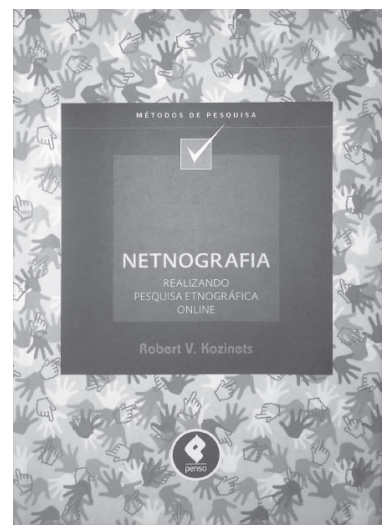

(Universidade Metodista de São Paulo, Faculdade de Comunicação, Programa de Pós-Graduação em Comunicação Social. São Bernardo do Campo - SP, Brasil)

KOZINETS, Robert. V. Netnografia: Realizando pesquisa etnográfica online. Porto Alegre: Penso, 2014. 203p.

N etnografia: Realizando Pesquisa Etnográfica Online é um livro precursor em que Robert V. Kozinets, professor de marketing da Universidade Iorque de Toronto, apresenta uma abordagem metodológica para a realização da netnografia.

Netnografia é uma forma especializada de etnografia e utiliza comunicações mediadas por computador como fonte de dados para chegar à compreensão e à representação etnográfica de um fenômeno cultural na Internet. Sua abordagem é adaptada para estudar fóruns, grupos de notícias, blogs, redes sociais etc.

A obra aqui exposta procura ilustrar a conduta de etnografia de comunidades e culturas virtuais e está estruturada em dez capítulos. O texto segue esta organização, porém, com ênfase nos 
capítulos que tratam sobre a questão do método. Os cinco primeiros trazem uma abordagem geral sobre os conceitos de comunidades e culturas online, visando incluir o leitor no universo da Comunicação mediada por computador e das pesquisas aplicadas à Internet. Do quinto capítulo em diante, como veremos a seguir, o autor discute e apresenta o conjunto de diretrizes específicas para o desenvolvimento de netnografias criativas e responsáveis.

O netnógrafo tem importantes decisões a tomar antes do primeiro contato com uma comunidade online. $\mathrm{O}$ procedimento de entrada, ou entrée cultural, parte de decisões sobre questões e temas, sobre a formulação da pergunta de pesquisa e visa a preparação para o trabalho de campo, tais como a identificação da comunidade online ou grupo a ser pesquisado. Inicialmente as formas de interação social e comunidades devem ser investigadas usando mecanismos de busca e outros meios e, ainda, o reconhecimento do campo e a forma como o pesquisador se apresentará ao grupo pesquisado são decisões fundamentais.

Durante a coleta e análise de dados três tipos de capturas são importantes: dados arquivais, dados extraídos e dados de notas de campo. A primeira coleta consiste em copiar diretamente de comunicações mediadas por computador dados da página, blog, site da comunidade ou grupo observado, assim como fotografias, trabalhos de arte e arquivos de som, dados cuja criação e estimulação o pesquisador não esteja diretamente envolvido. A segunda coleta refere-se aos dados extraídos que o pesquisador cria por meio da interação com os membros, tais como dados levantados por meio de entrevistas por correio eletrônico, batepapo, mensagens instantâneas etc. O terceiro tipo de coleta diz respeito às notas de campo experienciadas pelo pesquisador, sobre as práticas comunicacionais dos membros das comunidades, suas interações, bem como a própria participação e o senso de afiliação do pesquisador etc.

Kozinets afirma que a análise de dados contempla o processo de transformar os produtos coletados da participação e da observação netnográfica, como os arquivos de texto e gráficos baixados, capturas de tela, transcrições de entrevistas online e as 
notas de campo reflexivas, em uma versão acabada da pesquisa. Nas etapas de seleção, coleta e análise de dados o autor utiliza em suas pesquisas vários tipos de ferramentas, tais como mecanismos de busca como Google, incluindo Grupos do Google, Google Trends e Google Social Search, Twitter etc. Também utiliza pacote de software de análise dos dados qualitativos (CAQDAS), como o Atlas.ti e o Nvivo.

Na pesquisa netnografia ética (KOZINETS, 2014, p.132) quatro passos são importantes: identificar-se e informar os constituintes relevantes sobre a pesquisa; pedir permissões apropriadas; obter consentimento quando necessário; citar e dar o devido crédito aos membros.

Kozinets comenta sobre normas, avaliação e netnografia. Explica que para a compreensão e geração de critérios para a avaliação netnográfica é necessário o entendimento sobre os vários padrões históricos que sinalizaram a etnografia de qualidade. Tratase de fases que continuam influenciando a atualidade. Ele fala em oito momentos históricos: "tradicional, modernista, gêneros indistintos, crise da representação, pós-moderno, pós-experimental e o presente metodologicamente impugnado" (KOZINETS, 2014, p.149-150). Com a apresentação desses momentos históricos, Kozinets visa ao entendimento de noções correntes sobre o que é exigido de uma netnografia.

O autor aponta dez critérios definidos para avaliar e inspirar a qualidade netnográfica. Eles decorrem dos padrões etnográficos tradicionais e de sua situação presente, são eles: coerência, rigor, conhecimento, ancoramento, inovação, ressonância, verossimilhança, reflexividade, práxis e mistura. Esses critérios, segundo o autor, representam uma orientação pragmática como se fosse um kit de ferramentas para auxiliar na avaliação da netnografia, nas discussões acadêmicas e na construção de ideias. E ainda, propõe a validação do relatório de pesquisa junto ao grupo pesquisado. A apresentação da pesquisa tem o intuito de validar as interpretações sobre as observações realizadas, e permitir que o pesquisado apresente suas opiniões sobre o que foi escrito e se está condizente com o contexto em que vivem. 
Robert Kozinets aponta ainda três áreas teóricas e temas gerais que podem ter importância crescente no uso da netnografia: a relação entre empresas e comunidades eletrônicas; as implicações sociais das comunidades online, sua presença, institucionalização e posse; e os diferentes usos sociais dos diferentes meios de interação online.

O autor é enfático ao dizer que a Internet mudou nossa realidade, como cidadão, consumidor, pensador, falante, denunciante, blogueiro, amigo, fã, estudioso, enfim, mudou a realidade de ser um membro da sociedade.

Em netnografia tem-se a possibilidade de encurtar as distâncias entre tempo e espaço, devido à própria dinâmica da Internet, em que os grupamentos sociais estão dispostos em rede. Tais grupamentos podem funcionar somente no espaço online, como também podem coexistir fora dele, no espaço offline. O que é interessante perceber na apropriação dos pressupostos da etnografia é o caráter investigativo e de observação da realidade do outro que continua presente na netnografia.

Rico em exemplos e ilustrações, o livro é uma introdução metodológica à abordagem cultural da pesquisa online para o estudo de culturas e comunidades digitais. Recomendado aos interessados em mergulhar neste universo cheio de novidades e incertezas. Em uma leitura fluída o autor nos conduz e prende nossa atenção a cada detalhe dos procedimentos metodológicos da netnografia.

\section{Suelen Aguiar Silva (autora da resenha)}

Publicitária, doutoranda em Comunicação Social pela Universidade Metodista de São Paulo, membro do Núcleo de estudos de Comunicação Comunitária e Local. Bolsista CNPq. E-mail: susuaguiar@yahoo.com.br 